\title{
ESKI UYGURCA DÖRT BRAHMAN ÖYKÜSÜNDEN BİR PARÇA
}

\section{A PASSAGE OF THE OLD UIGHUR FOUR BRAHMAN STORY}

Serkan ŞEN*

\begin{abstract}
$\ddot{O} z$
Eski Türkçe ürünler arasında Uygurlardan kalan yazmalar gerek içerik, gerek çeşitlilik gerekse dil bilgisi özellikleri açısından önemli bir yere sahiptir. Eski Uygurca metinler, bir yandan ortaya kondukları dönemin dil yapısını yansıtırken diğer yandan başta Budizm olmak üzere yeni kabul edilen dinlerin terim varlı̆̆ın yansıtan türetme ve aktarımları bünyelerinde barındırırlar. Bu açıdan Türkçenin tarihî birikimini aydınlatabilmek için yayımı yapılmamış Uygurca metinlerin aydınlığa çıkarılması gerekmektedir. Çalışmamızda Uygurca anlatılar arasında değerlendirilen, Almanya'daki Mainz Koleksiyonu'nda 752 numarayla kayıtlı yazmanın tanıtımı yapılarak harf çevirimini, yazı çevirimini, açıklamalarını ve dizinini kapsayan metin yayımı gerçekleştirilecektir. İçeriğinden yola çıkılarak tarafımızdan "Eski Uygurca Dört Brahman Öyküsü" şeklinde adlandırllan bu yazma söz varlığı açısından dikkat çekici bir muhtevaya sahiptir. Yazmada belli sözcüklere ilk defa rastlanırken bazı sözcükler daha önce görülmeyen kullanımlarıyla karşımıza çıkmaktadır. Bunların yanında eserde dinî terimlerin Türkçeye aktarımında benimsenen yaklaşım da ilgiye değerdir. Almanya'da başlayan Uygurca metin yayımcılı̆̆ı faaliyetlerine Türkiye odaklı katkı să̆laması beklenen bu çalışmayla dikkat çekici bir dil yadigârımız aydınlı̆̆a kavuşturulmuş olacaktır.
\end{abstract}

Anahtar Kelimeler

Eski Türkçe, Eski Uygur Türkçesi, Eski Uygur Türkçesi Metinleri, Çatik

\section{Abstract}

Among the old Turkish texts, the handwrittens from Uighurs have an important place in terms of content, variety and grammatical features. Old Uighur texts, on the one hand, show language structure of the period in which they were written, on the other hand they include derivations and translations showing the existence of terms of newly entered religions, especially Buddhism. In this respect, in order to enlighten the historical accumulation of Turkish, unpublished Uighur texts should be brought to light. In this study, the handwritten registered with the number 752 in the Mainz Collection in Germany, which is commented among the Uighur narratives, will be given demonstration and this text will be published including transliteration, transcription, explanations and index. Based on its content, this handwritten, which is called "Old Uighur Four Brahman Story" by us, has a remarkable content in terms of vocabulary. While certain words are encountered for the first time in this handwritten, some of these words appear with their use which has never been seen before. Furthermore, approach of religious terms' translation into Turkish is worthy of attention in

* Prof. Dr., 19 Mayıs Üniversitesi Fen-Edebiyat Fakültesi Türk Dili ve Edebiyatı Bölümü, serkansen@omu.edu.tr, ORCID: 0000-0002-2884-4753 
Serkan ŞEN

this text. Our an attractive language trophy will be clarified by this study which expected to contribute to Uighur text edition activities which began in Germany firstly Turkey-oriented.

\section{Keywords}

Old Turkish, Old Uyghur, Old Uyghur Texts, Jataka 


\section{Giriş}

Bu çalışmada üzerinde duracağımız Eski Uygurca el yazması, Berlin Bilimler Akademisi Turfan Araştırmaları Merkezi'nde Mainz 752 (T III 84-74) numarada kayıtlıdır. Yazmanın içeriğine değinen ilk araştırmacı Peter Zieme'dir. Zieme, Eski Türkçenin sözlüklerinden Dreonetjurkskiy Slovar'1 değerlendirdiği yazısında, eserin 152.-153. sayfalarında geçen çog "çoban değneği" ve çomak "sopa" sözcüklerinin ço- fiiline dayandırılabileceğini dile getirmiş; T III 84-74

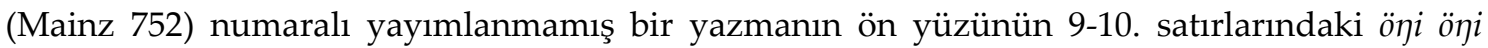
türlüg ... ät'özlärin çodılar ämgätdilär "Farklı farklı tarzda...bedenlerine vurup eziyet ettiler" ifadesinde ço-'in emget- "eziyet etmek" ile "vurup eziyet etmek" anlamında ikileme kurduğunu belirtmiştir (Zieme 1970: 231). Yine, Peter Zieme tarafından hazırlanan Berliner Turfantexte XIII'te "tirgin" sözcüğü açıklanırken yayımlanmadığı kaydıyla T III 84-74 (Mainz 752) numaralı yazmaya gönderme yapılmıştır (BT XIII: 1831 [114]). Budist öykü metinlerinin kataloğunu hazırlayan Jens Wilkens, çalışmasını '1. Daśakarmapathāvadāmālā Metinleri' ve '2. Diğer Öykü Metinleri' ana başlıklarına ayırırken 432. sırada ele aldığı Mainz 752 (T III 84-74) numaralı yazmayı '2. Diğer Öykü Metinleri' içinde, hangi kaynaktan çevrildiği belirlenemeyen '2.9. Çeşitli Öykü Metinleri' alt başlığı altında zikretmiştir (Wilkens 2010: 322). Wilkens'e göre metnin sayfa ölçüleri ve kağıt türü Daśakarmapathāvadāmālā kopyalarına uyum gösterse de bunu kesin olarak söylemek oldukça güçtür. Özellikle sayfa numarasının yazıldığı arka yüzde, yüzler basamağına denk gelen kısmın yırtık oluşu ...] bir kırk p(a)t(a)r "otuz birinci yaprak" ifadesinden önceki rakamı, dolayısıyla da metnin yer aldığı kitapta hangi sayfada bulunduğunu (bu 131 veya 231 olabilir) belirlememizi engellemektedir (Wilkens 2010: 322). Nitekim araştırmacı, 2016 yılında neşrini gerçekleştirdiği Daśakarmapathāvadāmālā metinleri içinde Mainz 752 numaralı yazmayı ele almayarak bu fikrini sürdürmüştür (Wilkens 2016).

\section{Metnin Fiziki Yapısı}

Berlin Bilimler Akademisi Turfan Araştırmaları Merkezi'nde, Mainz 752 (T III 84-74) kodu ile kayıtlı, oldukça büyük boy bir kitap sayfasının ölçülerinde olan el yazmasının ön yüzünün dışa gelen sol kenarında yıpranmalar vardır. ${ }^{1}$ En alt satırların bulunduğu kısım, hayli zarar görmüş olup yazmanın çeşitli yerlerinde kurt yeniğinden kaynaklandığını düşündüğümüz delikler bulunmaktadır. Yazmanın ön yüz, sol üst ve sağ alt kısmı ile alta yakın sol kısımlarında önemli yırtılmalar vardır. Gövde kısmı, alt ve üst kısımlara göre nispeten daha iyi durumda olup alt kenar boşluğu neredeyse yoktur. El yazmasının fiziki tanımına ilişkin Jens Wilkens' in verdiği aşağıdaki bilgilerin doğruluğu tarafımızdan da tespit edilmiştir.

Kağıt: Sarıya yakın orta kahverengi (gövde kısmı koyu kahverengiye yaklaşmakta) renkte, orta kalınlıkta, kırılgan, pürüzlü.

Satır sayısı: Önde ve arkada 36'şar satır

Satır aralığı: 1,3-1,5 cm.

Kırmızı kenar çizgisi güçlükle görülür.

Ebatları: 20,4 cm. (en), 51,0 cm. (boy).

Satır uzunluğu: $17,2 \mathrm{~cm}$.

Şahsıma yurt dışında araştırma imkânı sağlayan TÜBİTAK'a ve yazma üzerinde çalışmama izin veren Berlin Bilimler Akademisi Turfan Araştırmaları Merkezi (Berlin-Brandenburgischen Akademie der Wissenschaften Turfanforschung) yetkililerine bu vesileyle teşekkür ediyorum. 
Sayfaların birleştirilmesi için bırakılan deliğin çapı: 4,2 cm. Deliğin daire şeklindeki sınırlarını belirlemek için çizilen kırmızı çizgiden hemen hiçbir iz bulunmamaktadır. Bu delik için 7-9. satırlar arasında ayrılan kısım yırtıktır.

Bulunuş işareti: Ön üst sağ köşede T III (damga şeklinde), 84 (kurşunkalemle), ilave olarak 74 (kurşunkalemle).

Etiket kaydı: Mainz 752 ve T. III 84-74 (Wilkens 2010: 322).

\section{Metnin Ad1}

Metinde anlatılan öykünün adı yazmada geçmemektedir. “Eski Uygurca Dört Brahman Öyküsünden Bir Parça" adı, anlatının içeriğinden yola çıkılarak tarafımızdan verilmiştir.

\section{Metnin Kaynağı ve Çevirmeni}

Yukarıda değinildiği gibi metnin çevrildiği kaynak ve çevirmeni hakkında kesin yargılar ortaya koymak oldukça zordur. Bununla birlikte söz varlı̆̆ı ve yazım özelliklerinden yola çıkarak metnin çeviri süreci üzerine bazı değerlendirmeler yapılabilir. Eski Uygur Türkçesinde görülen Sanskritçe kökenli Budist terimler, büyük ölçüde Toharca aracilığıyla ödünçlenmiştir. Toharcanın A ve B şeklinde adlandırılan iki diyalekti bulunmaktadır. Sanskritçe sözcükler Toharcaya geçerken belli ses değişmelerine uğrarlar. Bu değişimler A ve B diyalektine göre farklılık arz eder. Örneğin, Sanskritçe sözcüklerin sonundaki a ünlüsü, A diyalektinde düşerken B diyalektinde è' ye dönüşür. -Skr. Ānanda Toh. A: Ânant/d; Toh. B: Anandè gibi (Moerloose 1980: 63)-. Metinde geçen brahm(a)lok < Skr. Brahmaloka, gavdam < Skr. Gautama, modak < Skr. modaka, padak < Skr. padaka, vèt < Skr. veda, vėtyastan < Skr. vidyāsthāna örneklerinde Sanskritçe sözcüklerin sonundaki ' $a$ ' sesinin düştüğü görülür. Bu durum, metnimizin Toharca A diyalektinden Uygurcaya çevrildiğini düşündürmektedir. Gelinen noktada, Ehlers kataloğunda "N Belgeleri" başlığıyla sıralanan ve bizim metnimiz gibi üçüncü Turfan seferinde elde edilip Mainz koleksiyonunda saklanan Daśakarmapathāvādanamālā yazmaları (Ehlers 1987: 16) dikkate değerdir. Kağıt türü, sayfa ebatları, satır sayısı, yazı ve yazım özellikleri açısından metnimizle büyük benzerlikler gösteren bu yazmaların Toharca A diyalektinden Uygurcaya çevrildiği bilinmektedir (Elmalı 2009: 2). Daśakarmapathāoūdanamālā yazmaları ile gözlenen bu paralellikler, elimizdeki metnin Toharca A diyalektinden Uygurcaya çevrildiği düşüncesini desteklemektedir. Daśakarmapathāvādanamālā metinlerinin çevirisi Şılazın Praşnıkı adlı çevirmen tarafından en geç 11. yüzyıl sonu 12. yüzyıl başlarında gerçekleştirilmiştir (Elmalı 2009: 4). Değinilen paralelliklerden yola çıarak metnimizin, Daśakarmapathā̃ādanamālā yazmalarıyla aynı tarihte ve aynı kişi tarafından Uygurcaya çevrildiği şeklinde bir iddia ortaya koymak mümkündür.

\section{Metnin Özeti}

Metinde, brahman cennetlerinde doğabilme arzusuyla bu dinin tanrılarına hizmet edip amaçlarına ulaşamayan dört bilge brahmanın öyküsü konu edinilir. Tüm çabalarına rağmen arzuladıkları cennetlere giremeyen brahmanlar, Buda'ya sadaka yemeği vermeleri sayesinde tüm isteklerinin yerine gelebileceğini işitmişlerdir. Sadaka yemeği olarak modak denilen bir tür şekerleme hazırlarlar. Ancak bir korkuları vardır. Sadaka verdikleri esnada Buda onlara vaaz edip akıllarını çelerse ne yapacaklardır? Bunun için şöyle bir karar alırlar: Sadaka yemeğini Buda'nın tasına koyduktan sonra kulaklarını tıkayıp hızla oradan uzaklaşacaklardır. Öyle de yaparlar. Buna rağmen Buda sadakayı bırakmaları ile kulaklarını tıkamaları arasında her birine bir cümle söyler. Birinciye " 'Sıkıntı' asiller gerçeğidir." der. İkinciye " 'Cemaat' asiller gerçeğidir." der. Üçüncüye " 'Sönme' asiller gerçeğidir." der. Dördüncüye ise " 'Yol' asiller gerçeğidir." der. Daha sonra brahmanlar toplanıp aralarında konuşmaya başlarlar. Her biri, 
diğerine ne söylendiğini merak etmektedir. Kendilerine söylenenleri anlatıp cümleleri sırasıyla birleştirdiklerinde aslında Buda'nın amacına ulaşıp vaazını gerçekleştirdiğini görürler. Önceki hayatlarında da Buda'nın nasihatlerini işitmişlikleri olduğundan Buda öğretisine iman ederler.

\section{Metnin Yazı ve Yazım Özellikleri}

Okunaklı bir el yazısıyla yazılan metinde nokta işareti (:) düzenli olarak kullanılmıştır. Kalın sıradan g sesi daima (q) işareti, kalın sıradan k sesi ise daima (q') işareti ile yazılmıştır. Kalın sıradan h sesi için (q) işareti tercih edilmiştir. "İşitmek" anlamındaki fiilin 'syd- (eşid-) ve 'ysyd- (eşid-) şeklinde farklı yazılması dikkat çekicidir. Uygurca metinlerde edgü kllınç biçiminde ayrı yazılan tamlamanın metinde, edgükılınç şeklinde bitişik yazılmasını, yazım yanlışı olarak değerlendirmek mümkündür.

\section{Metnin Yazı ve Harf Çevrimi}

\section{Mainz 752 (Ön)}

0101 törlüg vèt vètyas[tan twyrlwk vyt vyty'as[

02 biliglig al altag bi[rle pylyklyk "1 "lt'q py[

03 ler ning yörüginge [

$$
\text { l'r nynk ywrwkynk' [ }
$$

$04 \quad 04$ sansardakı alku savl[ar

$$
\text { s'ns'rd'qy "lquw s'vl[ }
$$

$8 \quad 08 \mathrm{t}(\mathrm{e})$ ngride ulatı $\mathrm{t}(\mathrm{e})$ ngrilerke [tapıg]

$$
\text { tnkryd' 'wl'ty tnkry l'rk' [ }
$$

09 udug kılıp öngi öngi törlüg

'wduq q"ylyp 'wynky 'wynky twyrlwk

1010 etözlerin çodılar emgetdiler: anta

$$
\text { 't'wyz l'ryn çwdyl'r 'mk'tdyl'r ," "nt' }
$$

1111 ötrü ol bramanlar bir ugurda bir ikintiş-

$$
\text { 'wytrw 'wl pr'm'nl'r pyr 'wqwrd' pyr 'ykyntys }
$$

1212 ke inçe tèp tėştiler: şakilarnıng ogl[1]

k' 'ynç' typ tysyty l'r: s'ky l'r nynk 'wql[ ] 
twyk'l lyk k'vd'm 'wqwslwq twyyn p'r 'rmys

1515 kim kayu kişi anga[r] azkı(y)a erser yme kym q"yw kysy "nk' [ ] "zqy a 'rs'r ym'

1616 buşı pinvat bèrip kut kolunsar ne kü[süşi] pwsy pynv't pyryp quwt q"wlwns'r n' kw[ ]

1717 erser köngül èyin kanar tèp tèrler: anın 'rs'r kwnkwl 'yyyn q"n'r typ tyr l'r,", "nyn

1818 biz ol gavdam uguşlug toyınka birer birer pyz 'wl k'vd'm 'wqwslwq twyynq" pyr'r pyr'r

1919 modak aş yaratıp pinvat buşı bèrelim bizmwd'k "s y'r'typ pynv't pwsy pyr'lym byz

2020 ing ne erser küsüşümüz erser utgurak köngül ynk n' 'rs'r kwyswswmwz 'rs'r ' wtqur'q" kwnkwl

2121 èyin kangay: yene ök inçe tèp tẻdiler 'yyyn q"nq'y," y'n' 'wk 'ynç' typ tydyl'r

2222 kim birök gavdam toyınka pinvat buşı bè[rser] kym pyrwk k'vd'm twyynq" pynv't pwsy py[ ]

23 angar nom nomlayur tèp tèrler: bizing bo "nk'r nwm nwml'ywr typ tyrl'r, pyzynk pw

24 [ye]ne(?) nomumuz yėg adruk ol neçök [e]rser [ ] ] $n^{\prime}$ nwmwmwz yyk "drwq"'wl n'çwk [ ]rs'r r 25 gavdam bizing yėg edgü kürümüzni kuna k'vd'm pyzynk yyk 'dkw kwyrwmwzny q"wn'

2626 alıp öz nomınta turgurmazun modak [aşıg] "lyp 'wz nwmynt' twrqwrm'zwn mwd'k [ ] 27 bèrgeli bardukta birök nom [nomlasar] pyrk'ly p'rdwq't' pyrwk nwm[

2828 neçök kılur biz: yene ök n[om nomlasar] n'çwk quylwr pyz,, y'n' 'wk n[

2929 biz törtegü anıng nomın tı[nglamatın birer] pyz twyrt'kw "nynk nwmyn ty[

3030 birer yügürüp pinvat aş pat(1)rınta [uralım] pyr'r ywkwrwp pynv't "s p'trynt' [ ]

$3131 \mathrm{t}(\mathrm{e}) \mathrm{rkin}$ ök kulkakım(1)znı tuyu tezelim: mu[ntag] trkyn 'wkq"wlq" qymz ny twyw t'z'lym,, mw ]

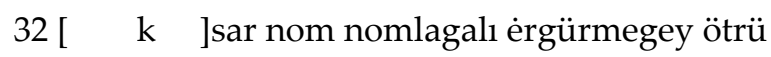
[ q" ]s'r nwm nwml'q'ly 'yrkwrm'k'y 'wytrw

3333 [bramanlar b]o muntag kèngiş ken[g]şeşip eng [ ] ] mwnt'q k'nkys k'n[k]s'syp "nk 
34

34 [başlayu bi]r braman modak aş [alı]p yügürüp

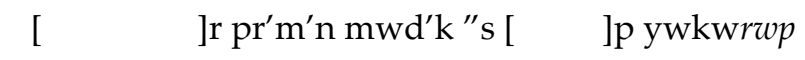

3535 [ tengri] burhanka patı[rınta ur]d $\imath$ [ötrü]

[ ] ] pwrq'nq" p'ty[ ]dy [ ]

3636 [tengri burha]n katıg ü[nin inçe tèp nomlamış emgek]

Mainz 752 (Arka)

$$
\text { ]n q"tyq'w[ ] ] }
$$

...] pyr bir q"yrq" ptr

...] bir kirk p(a)t(a)r

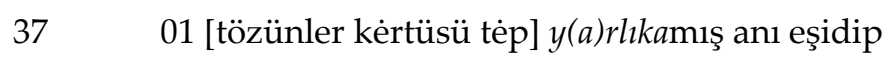

$38 \quad 02$ [ol braman iki kulkakın] tuyu tezip yügürüp

[ ] ] twyw t'zyp ywkwrwp

3903 [ bardı: anta ötrü ikinti] braman modak aş

[ ] ] pr'm'n mwd'k"s

$40 \quad 04$ [alıp $\mathrm{t}(\mathrm{e})$ ngri burhan] patırınta urdı: $\mathrm{t}(\mathrm{e})$ ngri

[ ] ] ] p tyrynt' 'wrdy,, tnkry

4105 [burhan inçe tèp ya]rlıkadı: tèrkin tözün-

[ ] ]rlyq"dy,, tyrkyn twyzwn

$4206 l[$ er] kèrtüsü tèp munı ėşidip ol braman yme

$l[$ ] kyrtwsy typ mwny 'sydyp wl pr'm'n ym'

$43 \quad 07$ iki kulkakın tuyu tezip bardı: anta

'yky q"wlq" qyn twyw t'zyp p'rdy," "nt'

4408 [öt]rü üçünç braman yme modak

[ ]rw 'wyçwnç pr'm'n ym' mwd'k

$45 \quad 09$ [aş] alıp t(e)ngri i burhanka yakın

[ ] "lyp tnkry y pwrq'nq" y'qun

4610 barıp patırınta urdı: yene ök $t(e) n g r i ~ b u r h a n$

p'ryp p'tyrynt' ‘wrdy," $y^{\prime} n^{\prime}$ ' wk tnkry pwrq'n

4711 öçmek tözünler kèrtüsü tèp y(a)rlıkadı: ol

'wyçm'k twyzwnl'r kyrtwsy typ yrlıq" dy," 'wl

$48 \quad 12$ üçünç braman yme iki kulkakın tuyu

'wyçwnç pr'm'n ym' 'yky q"wlq"aq"yn twyw

4913 tezip bardı: ötrü törtünç braman modak

t'zyp p'rdy," 'wytrw twyrtwnç pr'm'n mwd'k

$50 \quad 14$ aş alıp $t(e) n g r i$ burhan patırınta urdı:

"s "lyp tnkry pwrq'n p'tyrynt' 'wrdy "y

$5115[\mathrm{t}(\mathrm{e}) \mathrm{n}] \mathrm{gri}$ burhan inçe tèp y(a)rlıkadı: yol töz- 
[ ]kry pwrq'n 'ynç' typ yrlyq"dy „, ywl twyz

52

53

54

55

56
16 [ünle]r kèrtüsü tėp ol braman yme iki kul-

[ ]r kyrtwsy typ 'wl pr'm'n ym' 'yky qul

$17 \mathrm{k}[\mathrm{a}] \mathrm{kn}$ tuyu yügürüp tezip bardı: anta ötrü

q[ ]qy'yn twyw ywkwrwp tyzyp p'rdy," "nt' 'wytrw

18 ol bramanlar yıgılıp sıp bir ikintike inçe

'wl pr'm'nlar yyqylyp syp pyr 'ykyntyk' 'ynç'

19 tèp tėştiler: gavdam toyın negü tèdi erki:

typ tysty l'r," k'vd'm twyyn n'kw tydy 'rky ",

20 bir braman inçe tèp tèdi: manga emgek töz-

pyr pr'm'n 'ynç' typ tydy," m'nk' 'mk'k twyz

21 [ü]nler kèrtüsi tèp tèdi: anta ok iki kulkak-

[ ]n l'r kyrtwysy typ tydy," "nt"wq"'yky q"wlqaq"

$221 m[1 n]$ tuyu tezdim: ikinti braman inçe tẻp

ym[ ] twyw t'zdym,, 'ykynty pr'm'n 'ynç' typ

23 tẻdi manga tèrkin tözünler kèrtüsi tèp tydy m'nk' tyrkyn twyzwnl'r kyrtwsy typ

24 sözledi: üçünç braman inçe tèp tėdi[:] swyzl'dy ,' 'wyçwnç pr'm'n 'nç' typ tydy []

25 manga öçmek tözünler kèrtüsü tèp nomladı: m'nk' 'wyçm'k twyzwnl'r kyrtwsy typ nwml'dy,

26 t[örtün]ç br[a]man antag sözledi: manga yol

t[ ] ] br br[ ]man "nt'q swyzl'dy „, m'nk' yol

27 [tözünler kèrtüs]i tèp sözledi: ötrü braman-

[ ]y typ swyzl'dy,, 'wytrw pr'm'n

28 [lar bo tört $\mathrm{p}(\mathrm{a})$ ]dak nomug birle kavşurdı

]d'k nwmwq pyrl' q"vswrdy

29[

]' yme öngre ajuntakı burhan-

[

l' ym' 'wnkr' "jwnt'qy pwrq'n

30 [lar no] $m[1] n$ yme esşidmişleri bar üçün edgükılınç-

[ ] $m[y] n y^{\prime} m^{\prime}$ ysydmysl'ry p'r 'wyçwn 'dkwq"ylynç

31 ları köngüllerinte tamıtıp kelti: bo tört

l'ry kwnkwll'rynt' t'mytyp klty „, pw twrt

$32 \mathrm{p}(\mathrm{a})$ dak nomug birle kavşurup köngüllerin

pd'k nwmwq pyrl' q"vswrwp kwnkwl l'ryn

33 kèng alkıg [t]ering yörügde '[

bir]

kynk "lq"yk [ ]'rynk ywrwgd' '[

34 [iki]ntik[e in]çe tèp tèštiler: [

[ ]nty k[ ] ] typ tysty l' $\mathrm{r}_{\text {, }}$ [ 


$\begin{array}{rrcc}71 & 35[ & \text { ]/ şakilar nomi [ } & \\ 72 & 36[ & \text { ]/ s'kyl'r nwmy[ } & ] \\ & {[} & \text { ]k ol: ol } & \\ & & \text { ]k 'wl ,'wl[ } & ]\end{array}$

\section{Metnin Çevirisi}

1 Türlü veda, vidyā-sthāna.................... 2 bilgili beceri ve hüner ile................... 3 -lerin yorumuna................. 4 Samsara'daki bütün sözler............... 5 ile tutan dört brahman.............. 6 Bunun üzerine o brahmanlar Brahmaloka tanrı yerinde 7 doğma arzusuyla Visnnu, Maheśvara 8 tanrılardan başka (pek çok) tanrılara hizmet 9 ve hürmet edip farklı farklı türden 10 bedenlerine vurup eziyete girdiler. Ondan 11 sonra o brahmanlar bir gün bir -12- birlerine şöyle söyleyerek konuştular: “'Śākya (kabilesinin) evladı 13 görülesi güzellikte, soylu ve asil, saf öğretiye 14 sahip, Gautama soyundan rahip var imiş. 15 Hangi kimse ona azıcık olsa bile 16 sadaka yemeği verip saadet dilese ne dileği 17 var ise (dilekleri) gönlüne göre kanar (imiş).' diye söylerler. Onun için 18 biz o Gautama soyundan rahibe birer birer 19 Modaka aş1 hazırlayıp sadaka yemeği (olarak) verelim. 20 Bizim ne dileğimiz varsa şüphesiz gönlümüze 21 göre kanacak(tır)". Tekrar şöyle deyip konuştular: 22 " 'Kim Gautama rahibe (Budaya) sadaka yemeği verirse 23 ona öğretiyi vaaz edermiş.' diye söylerler. Bizim bu 24 mevcut öğretimiz daha üstün ve seçkindir. Sakın 25 Gautama (Buda) bizim bu üstün ve güzel usulümüzü çalarak 26 alıp kendi öğretisine mal etmesin? Modaka aşı 27 vermeye vardığımızda eğer öğretiyi vaaz ederse 28 biz ne yaparız? Şayet öğretiyi vaaz ederse 29 biz dördümüz onun öğretisini dinlemeden birer 30 birer yürüyüp sadaka yemeğini sadaka tasına koyalım. 31 Hemencecik kulağımızı tıkayıp uzaklaşalım. Böyle 32 ............sa öğretiyi vaaz etmeyi başaramaz." Bunun üzerine 33 brahmanlar böyle karar aldılar. İlk 34 önce brahmanlardan biri Modaka aş alıp, varıp 35 tanrı Buda'nın sadaka tasına koyduğunda 36 ardında tanrı Buda yüksek sesle şöyle vaaz etti: "Istırap,

\section{otuz birinci varak}

37 asiller gerçeğidir." diye buyurdu. Bunu işitip 38 o brahman iki kulağını tıkayarak uzaklaşıp, yürüyüp 39 gitti. Ondan sonran ikinci brahman Modaka aş 40 alıp tanrı Budanın sadaka tasına koyduğunda tanrı 41 Buda şöyle söyleyip buyurdu: "Cemaat, asiller $\mathbf{4 2}$ gerçeğidir." dedi. Bunu işitip o brahman da 43 iki kulağını tıkayıp uzaklaşıp gitti. Ondan $\mathbf{4 4}$ sonra üçüncü brahman da Modaka 45 aş alıp tanrı Budaya yakın 46 varıp sadaka tasına koydu. Yine hemen tanrı Buda 47 "Dinginleşme, asiller gerçeğidir." diye buyurdu. O 48 üçüncü brahman da iki kulağını tıkayarak 49 uzaklaşıp gitti. Sonra dördüncü brahman Modaka 50 aş alıp tanrı Budanın sadaka tasına koydu. 51 Tanrı Buda şöyle deyip buyurdu: "Yol, asiller 52 gerçeğidir." dedi. O brahman da iki 53 kulağını tıkayıp yürüyerek uzaklaşıp gitti. Bunun üzerine 54 o brahmanlar bir araya gelip toplanarak birbirlerine şöyle 55 söyleyip konuştular: "Gautama rahip (Buda) neler dedi ki?" 56 Bir brahman şöyle dedi: "Bana, 'Istırap, asiller 57 gerçeğidir.' diye söyledi. Hemen o anda iki kulağımı 58 tıkayıp uzaklaştım." İkinci brahman şöyle 59 dedi: "Bana 'Cemaat, asiller gerçeğidir.' diye 60 söyledi". Üçüncü brahman şöyle dedi: 61 "Bana 'Dinginleşme, asiller gerçeğidir.' diye vaaz etti." 62 Dördüncü brahman şöyle söyledi: "Bana 'Yol, 63 asiller gerçeğidir.' diye söyledi." Sonra brahmanlar 64 dört dizelik öğretiyi birleştirdi. 65 ........ Yine önceki hayatlarında Budalar 66 öğretisini işitmişlikleri olduğu için güzel amelleri 67 gönüllerinden damlayıp geldi. Bu dört 68 dizelik öğretiyi birleştirip gönüllerini 69 geniş ve yüce olan derin yorumda.............bir 70 diğerine şöyle deyip söyleştiler:....71......Şaki soyundan olanların öğretisi.........72 .................ır. 
O.

Notlar.

01 vèt: < Toh. ved (TD A: 283, TD B: 572) < Skr. veda Knowledge, true or sacred knowledge or lore, knowledge of ritual; name of certain celebrated works which constitute the basis of the first period of the Hindū religion (MW: 1015) "Bilgi, doğru ya da kutsal bilgi, irfan, ritüel bilgisi. Hindu dininin ilk döneminin temelini oluşturan bazı ünlü eserlere verilen ad."

01 vètyastan: < Toh. vidyāsthām (TD B: 571) < Skr. vidyāsthāna 'Subject of knowledge', one of the five 'sciences classiques' (BHSD: II-488) “(Eski Hindistan'da) gramer, mantık, din, tıp ve teknolojiden ibaret olan beş bilim dalının her biri"; branch of knowledge (MW: 964) "bilgi dalı".

06 brahm(a)lok: < Toh. Brahmalok (TD A: 209, TD B: 432) < Skr. brahmaloka The world or heaven of Brahmā (a division of the universe and one of the supposed residences of pious spirits) (MW: 739) "Evren ya da Brahma cenneti (evrenin bir bölümü ve dindar ruhların dinlendiği varsayılan yerlerden biri)". Jens Wilkens BT XXV'de 1089-1090 satırlardaki br(a)hmalok ezrua yertinçüsi ifadesinde br(a)hmalok sözünün ezrua yertinçüsi "brahman dünyası" tamlamasıyla ikileme kurduğunu belirtmiştir (Wilkens 2007: 123).

07 vişnu: < Toh. Viśnu (TD A: 282, TD B: 572) < Skr. Víshnu Name of one of the principal Hindū deities. In the later mythology regarded as "the preserver", and with Brahmā "the creator" and Śiva "the destroyer, constituting the well-known Tri-mūrti or triad; although Vishnu comes second in the triad he is identified with the supreme deity by his worshippers"... (MW: 999) "Hindu inancında en önemli tanrılardan birinin adı. Geç dönem Hint mitolojisinde Brahma, "yaratıc1", Śiva, "yok edici", Viṣnu ise "koruyucu" olarak kabul edilir. Tri-mūrti ya da üçleme olarak bilinen bu sıralamada (Brahmā-Viṣnu-Śiva) Viṣnu, ikinci sırada bulunsa da kulları tarafından yüce tanrı olarak tanımlanır". Sözcük, Uygurca metinlerde (TT X: 485 [34]; BT IX: 1v18 [26], 11826 [53]) örneklerinde karşımıza çıkar.

07 mahakişvari: < Toh. Mahiśvar / Mahiśvare (TD A: 216, TD B: 445) < Skr. Maheśvara, A devaputra, evidently a leader of the śuddhāvāsakāyika gods, with whom he comes to salute the infant Bodhisattva and predict his future Buddhahood. (BHSD: II- 427B) "Bir devaputra (tanr1 oğlu), śuddhāvāsakāyika (= devaputra 'tanrı oğlu') niteliğindeki tanrıların önde gelenlerinden biri. Onunla bebeklik çağındaki Budaya selam getirilir ve o, gelecekte bu bebeğin Buda olacağını tahmin eder. Sözcük, Sanskritçede mahā "büyük" ve işvara "efendi, tanrı" sözlerinin birleşiminden oluşmuştur (BT IX: [26]). Uygurca metinlerde mahişvar (BT III: 283 [40], maĥhişvar (TekinKuan: A115, 116 [14]), m'kysv'ry > mahişvari (Tiş: 734 [89], U II: 5 [53]) m'kyşvry BT IX: 15112 [121], $m^{\prime} k^{\prime}$ şvry (BT IX: 11826 [53], $m q^{\prime}$ şvry (BT IX: 1v18 [26]) türevlerine rastlanır. Sıralanan örneklerde, Toharca A diyalekti aracılığıyla ödünçlenen Sanskritçe sözcüklerin sonundaki 'a' ünlüsünün Uygurcada düşmesi ya da 'i'ye dönüşebilmesi kuralı (Moerloose 1980: 62-63) gözlenir. Sözcük, metnimizde ve zikredilen başka metinlerde farklı yazımlarla geçer. Bu durum, Toharca konuşan hocalardan işiterek öğrendikleri Sanskritçe kökenli sözcükleri (Moerloose 1980: 75) Uygurcaya aktaran çevirmenlerin kendi telaffuzlarını esas almış olmalarıyla açıklanabilir.

10 ço-: Sözcük metinde çodılar emgetdiler "Eziyet ettiler." ikilemesinde geçmektedir. İkilemenin diğer unsuru emget-'in "1stırap vermek" karşılığından hareketle ço-'a "vurmak, acı vermek" anlamı verilebilir. Nitekim Peter Zieme, metindeki çodılar emgetdiler ikilemesini "Vurup eziyet ettiler." şeklinde anlamış ve ço- fiilinin çomak "sopa" sözünü aydınlatabileceğini belirtmiştir (Zieme 1970: 231). Marcel Erdal, OTWF'da fiili, çu- şeklinde okusa da (OTWF: 646) daha sonra ço- okuyuşunu benimsediğini tarafımıza ifade etmiştir. Sözcük, "vurmak, 
saldırmak" anlamıyla TT VIII'de küçin kün çogı çomakta ötkürü sarıg terilür "...Şiddetli güneş 1şınlarının vurmasından ötürü safra toplanır." (TT VIII: I23 [59]), Maytrısimit'te amarıların tarta eşe tokıyu toฑ[layu] çoyu belgürtür "Diğerlerini çekip alarak, vurup döverek, 1stırap vererek ortaya çıkarır." (BT IX: 16511-12 [149]) ifadeleriyle örneklendirilebilir. Eski Türkçedeki ço-n"1stırap çekmek" (ETŞ: 976 [76]); ço-l- "incinmek, acı duymak" (SuvKaya: 3691 [219]; 50016 [275]); ço-k- "vurmak, öldürmek" (KP Hamilton: III1 [28]; VIII: C5 [26]), "inmek, konmak" (DLT: 272 (II 396) fiillerini, ço-'tan türeyen sözcükler olarak görmek mümkündür. Tarafımızdan hazırlanan "Kutadgu Biligde Geçen Çomak 'Müslüman' Sözü Üzerine”, başlıklı çalışmada sözcük ve türevleriyle ilgili geniş bilgiler verilmiştir (Şen 2011).

14 gavdam: < Toh. Gautam (TD A: 445, TD B: 246) < Skr. Gautama (also written Gotama) gotra-name of Śäkyamuni, often applied to him especially by those who are not his followers" (BHSD: II-218). “Gautama ya da Gotama, Buda'nın ait olduğu kabilenin adı. Özellikle Buda'nın takipçisi olmayanlar sık sık onun için bu ada müracaat ederler. Metnin 25. satırında geçen gavdam bizi门 yeg edgü kürümüzni kuna alıp ifadesinde Brahmanlar, Buda'yı adlandırırken bu sözcügü kullanmışlardır.

19 modak: < Toh. ? < Skr. modaka A small round sweetmeat, any sweetmeat (MW: 835) "Küçük yuvarlak şekerleme, bir tür şekerleme".

30 patır: < Sogd. p'ttr < Skr. pātra Budist rahiplerin sadaka tası. Sözcük "çanak, tas" anlaminda Uygur sivil belgelerinde de görülür (EDPT: 307). Uygurca metinlerde sözcüğün ikinci ünlüsü zaman zaman yazılmayabilir. Metinde 30. satırda ikinci ünlü yazılmamışken 35, 40,46 , 50. satırlarda ' 1 ' ünlüsünün yazıldığ 1 görülür.

33 kẻngşeş-: "Danışmak, istişare etmek". Metinde sözcüğün bulunduğu bölüm kısmen yıpranmış olsa da okunabilen harflerden ve yıpranan kısmın ebatlarından yola çıarak ken[g]şeşip okuyuşuna ulaşmak mümkündür. Fiilin kéngiş+e-ş- şeklinde türediği anlaşılmaktadır (OTWF: 272).

54 s1-: Sözcük metinde yıgılıp sıp "toplanıp, bir araya gelip" ikilemesinde geçmektedir. Eski Türkçede genellikle "kırmak, parçalamak" anlamı taşıan st- fiilinin, ikilemede "toplanmak, birikmek" karşılığında yer alması dikkate değerdir. st-'ın, yıgıl- "yığılmak, birikmek, toplanmak" ile benzer anlamda kullanılışı ilk kez görülen bir durumdur. Fiilin "toplanmak, bir araya gelmek" anlamı, Türkiye Türkçesindeki "seyrek karşıtı; kesif, yoğun" karşılığında bulunan sık niteleyicisinde ve sık- "tazyik etmek" fiilinde muhafaza edilmiştir. Eski Türkçede fiillere gelen -(O)k ekinin sıfat (OTWF: 224); -(X)k- ekinin ise kuvvetlendirme yaptığı (OTWF: 649) düşünülürse st- "toplanmak" fiili ile st- $k$ ve st-k- sözcükleri arasındaki ilişki daha kolay anlaşılabilir. Tarafımızdan yayınlanan “ 'Sık' Sözcüğünün Kökeni Üzerine” başlıklı makalede sı- fiilinin metnimizde görülen bu yeni anlamıyla ilgili daha geniş bilgiler sunulmuştur (Şen 2012).

\section{Sonuç}

Almanya'da bulunan Eski Uygurca el yazmaların kataloglama projesi önemli mesafeler katetmiştir. Alttürkische Handschriften adıyla seri halinde kitaplaştırılan kataloglarda, dökümü yapılan yazmaların yayımlanıp yayımlanmadığı bilgisine de yer verilmektedir. Alttürkische Handschriften serisi üzerinde gerçekleştirdiğim tarama sonucunda, henüz yayımlanmamış en hacimli yazma parçasının makalede ele alınan Mainz 752 (T III 84-74) numarada kayıtlı metin olduğu tespit edilmiştir. Bu çalışmayla, değinilen yazmanın metin yayımı gerçekleştirilmiş, Eski Türkçenin söz varlığına katkı sağlayacak verilere ulaşılmıştır. ço- "vurmak, acı vermek" fiili kök hâlinde açıkça tanıklanmış, sık "seyrek olmayan" sözcügü ile st- fiili arasında ilişki 
kurabileceğimiz bir kullanıma tesadüf edilmiştir. Budist Uygur anlatılarının sınırlarını daha da ileri taşıdığını düşündügümüz metinin başka parçalarına ulaşıldığı takdirde yeni değerlendirmeler yapmak mümkün olabilecektir.

\section{Summary}

Among the old Turkish texts, the handwrittens from Uighurs have an important place in terms of content, variety and grammatical features. Old Uighur texts, on the one hand, show language structure of the period in which they were written, on the other hand they include derivations and translations showing the existence of terms of newly entered religions, especially Buddhism. In this respect, in order to enlighten the historical accumulation of Turkish, unpublished Uighur texts should be brought to light. In this study, the handwritten registered with the number 752 in the Mainz Collection in Germany, which is commented among the Uighur narratives, will be given demonstration and this text will be published including transliteration, transcription, explanations and index. Peter Zieme was the first researcher to address the content of the manuscript. Zieme referred to this article in his review of Drevnetjurkskij Slovar, one of the old Turkish dictionaries. Jens Wilkens, who prepared the catalog of Buddhist short stories, handled this manuscript in "OtherStory Texts" under the subtitle "Various Story Texts", from which the source could not be determined. There is wear on the left edge of the front of the manuscript, which is the size of a very large book page. The part where the bottom lines are located is highly damaged and there are holes in the writing that we think are caused by the new wolf. There are significant tears on the front face, upper left and right lower parts of the writing and the left parts near the bottom. The body portion is relatively better than the lower and upper portions, with virtually no lower margin.

Based on its content, this handwritten, which is called "Old Uighur Four Brahman Story" by us, has a remarkable content in terms of vocabulary. While certain words are encountered for the first time in this handwritten, some of these words appear with their use which has never been seen before. Furthermore, approach of religious terms' translation into Turkish is worthy of attention in this text. Our an attractive language trophy will be clarified by this study which expected to contribute to Uighur text edition activities which began in Germany firstly Turkey-oriented. The project to catalog the Old Uighur manuscripts in Germany has come a long way. The catalogs cataloged in series under the name of Alttürkische Handschriften also include information on whether or not the manuscripts have been published. As a result of my research on the Alttürkische Handschriften series, it has been found that the most voluminous piece of paper that has not yet been published is registered in Mainz 752 (T III 84-74). In this study, the text of the mentioned manuscript was published. 


\section{Dizin}

adruk: Ayrı, seçkin.

yèg a. 24

ajun: < Sogd. "'žwn Varlık şekli, yaşam, dünya.

öngre a.+tak1 65

al: Yöntem, hüner, çare.

a. altag 02

al-: Almak.

a.-1p [34], [40], 45, 50

kuna a.-1p 26

alku: Hep, bütün, her.

a. 04

altag: Yöntem, hüner, çare.

al a. 02

anı: Onu.

a. 37

anın: $\mathrm{O}$ nedenle.

a. 17

anıng: Onun.

a. 29

anta: Ondan, oraya, orada.

a. ok 57

a. ötrü 10, [39], 43, 53

antag: Şöyle, şu şekilde.

a. 62

angar: Ona.

a. $1[5], 23$

arıg: Temiz, saf, arı.

a. çahşapatka 13

aș: Yemek, aş.

pinvat a. 30

modak a. 19, 34, 39, [45] 50

modak a.+1g[26]

azkıya: Azıcık.

a. 15

alkıg: Yüksek.

kèng alkıg 69

bar: Var, mevcut.

b. ermiş 14

b. üçün 66

bar-: Varmak, gitmek.

b.-d1 [39], 43, 49, 53

b.-dukta 27

b.-1p 46

başlayu: Başlangıçta, önce. eng b. [34]

bèr-: Vermek.

b.-geli 27

pinvat buşı b.-elim 19

pinvat buşı b.- ser 2[2]

buşı pinvat b.-ip 16

biliglig: Bilgili.

b. 02

bir: Bir.

b. ugurda 11

b. braman 3[4], 56

b. ikintişke 11

b. ikintike $54,[69]$

b. kırk 36-37

birer: Birer.

b.birer [29], 18

birer b. 30, 18

birle: İle, vasitasıyla.

al altag b. $0[2]$

umug b. 64,68

birök: Şayet, eğer.

b. 22,27

biz: Biz.

b. $18,28,29$

bizing: Bizim

b. $19,23,25$

bo: $\mathrm{Bu}$.

b. $23,3[3], 67$

brahm(a)lok: < Toh. Brahmalok < Skr. Brahmaloka Evren ya da Brahma cenneti.

b. 06

braman: < Toh. brāmam < Skr. brāhmaṇa

Brahman din adamı.

b. $0[5], 34,[38], 39,42,44,48,49,52,56,58$,

60,62

b.+lar 06, 11, [33], 50, 54, 63

burhan: Buda.

b. 3[6], [40], [41], 46, 50, 51,

b.+ka 35,45

b. +lar 65

buşı: < Çin po-şi Sadaka.

b. pinvat bèrip 16

pinvat $b$. bèrelim 19

pinvat b. berser 22

çahşapat: < Sog. çihşāpad < Skr. śikśāpada

Ögreti, aklak kaidesi, on yasak. 
arıg ç .+ka1[3]

ço-: Acı vermek.

ç.- dılar emgetdiler 10

edgü: Güzel, iyi.

e.k1lınçları 66

yèg e. 25

emgek: Acl, 1stırap.

e. [36], 56

emget-: Acı vermek, 1stıraba düşürmek.

çodılar e.-diler 10

eng: En, ilk.

e. başlayu 33

er-: İmek, yardımcı eylem, olmak.

e.-miş 14

erki: Acaba, galiba, herhalde.

e. 55

e.-ser 15, 17, 20, 2[4]

eşid-: İşitmek. bk. èşid-

e.-ip 37, 42

etöz: Beden.

e. +lerin 10

gavdam: < Toh. Gautam < Skr. Gautama ya da Gotama Buda'nın ait olduğu kabile adı. 25

g. uguşlug toyın 14,18

g. toyınka 22,55

èrgürme-: Gücü yetmemek, başaramamak.

e.-gey 32

ėşid-: İşitmek, duymak.

è.- mişleri bar 66

èyin: Uyarınca, göre.

köngül è. 17, 21

iki: İki.

i. [38], 43, 48, 52, 57

ikinti: İkinci.

i. [39]

ikinti: İkinci.

i. 58

bir i.+şke 11

bir i.+ke 54, 7[0]

inçe: Şöyle.

i. tèp12, 21, [36], [41], 51, 54, 56, 58, 60 7[0]

kan-: Kanmak, tatmin olmak.

köngül ėyin k.-ar 17

köngül èyin k.-gay 21

katıg: Sert, yüksek, kararlı.

k. ün 36 kavşur-: Birleştirmek.

k.-d1 64

k.-up 68

kayu: Hangi.

kim k. 15

kel-: Gelmek.

k.-ti 67

kèng: Geniş.

k.alkıg 69

kèngiş: Danışma, istişare.

k. kėngşeşip 33

kẻngşeş-: Danışamak, istişare etmek.

kèngiş k.-ip 33

kèrtü: Gerçek, hakikat.

tözünler k.+si [37], 42, 47, 52, 57, 59, 61 [63]

kıl-: Kılmak, yapmak.

tapig udug k.-1p 09,

neçök k.-ur 28

kılınç: İș, amel.

edgük.+ları 66

kırk: Kırk.

k. 36-37

kim: Kim.

k. 22

k. kayu 15

kişi: Kişi, kimse.

kim kayu k. 15

kolun-: Dilemek, istemek.

kut k.-sar 16

köngül: Gönül.

k.+lerin 68

k.+lerinte 67

k. èyin kanar 17

k. ėyin kangay 20

kör-: Bakmak.

k.-geli körtle 13

körtle: Güzel.

körgeli k. 13

kulkak: Kulak.

k.+1min tuyu 57

k.+1miznı tuyu 31

k.+1n tuyu [38], 43, 48, 52

kun-: Çalmak.

k.-a alıp 25

kut: Kut, saadet.

k. kolunsar 16

kür: Yöntem, tarz. 
k.+ümüzni 25

küsüş: Arzu, istek.

k.+i 16

k.+in 07

k.+ümüz 20

mahakişvarı: < Toh. Mahiśvaré < Skr. Maheśvara Budist metinlerde geçen tanrilardan birinin adi.

m. 07

manga: Bana.

m. 56, 59, 61, 62

modak: < Toh ? < Skr. Modaka Bir tür şekerleme.

m. aş 19, 26, 34, 39, 44, 49

muntag: Bunun gibi, böylesi.

m. 3[1], 33

munı: Bunu.

m. 42

ne: $\mathrm{Ne}$.

n. küsüşi erser 16

n. erser 20

neçök: Nasıl.

n. 24,28

negü: Ne.

n. 55

nom: < Sog. nom < Gr. nomos Din, öğreti, şeriat.

n. + in 29

n.tug 64,68

n. + umuz 24

n. nomlasar 27, 2[8]

n. nomlayur 23

n. nomlagalı 32

burhanlar n.+1n 6[6]

öz n.+1nta 26

şakilar n.+1 71

nomla-: Vaaz etmek.

n.-d1 61

n.-mış [36]

nom n.-galı 32

nom n.-yur 23

nom n.-sar [27], [28]

ogul: Oğul, evlat.

şakilarnıng $0 .+1$ 1[2]

ok: Pekiştirme edatı.

anta o. 57 ol (1): O (İşaret sıfatı görevinde).

o. $06,11,18$, [38], 42, 47, 52, 54

ol (2): -Dir (Bildirme eki görevinde).

öçmek: Sönme, dinme.

ö. 47, 61

ök: Pekiştirme edatı.

terkin ö. 31

yene ö. 21, 28, 46

öngi: Başka, farklı.

ö. öngi 09

öngre: Önce, önceki.

ö. ažuntakı 65

ötrü: Sonra, bunun üzerine.

ö. 0[5], [35], 32, 49, 63

anta ö. 11, [39], 4[4], 53

öz: Öz, kendi.

ö. nominta 26

padak: < Toh. pādak< Skr. padaka Şiir, manzume, dize.

p. nomug 6[4], 68

p(a)t(a)r: < Toh. patrak < Skr. pattram

Yaprak, varak, kitap sayfası.

36-37

patır: < Sogd. p'ttr < Skr. pātra Budist rahiplerin sadaka tası.

p.+1nta uralım 30

p.+1nta urdi 3[5],40,46, 50

pinvat: $<$ Toh. pinvāt $<$ Skr. pinḍapata

Sadaka olarak verilen yemek.

buşı p. bèrip 16

p. aş 30

p. buşı bèrelim 19

p. buşı bèrser 22

sansar: Toh. samsar < Skr. samsara Varlıklar dünyası, yeryüzü, doğum-ölüm döngüsü.

s.+dak1 04

sav: Söz.

s.+lar 0[4]

s1-: Toplanmak, bir araya gelmek.

y1gilıp s.-p 54

sözle-: Demek, söylemek.

s.-di $60,62,63$

şaki: < Toh. Śākke < Skr Śākya Buda'nın

geldiği aile veya boyun adi.

ş.+lar nom 71

ş.+larning ogli 12 
tamit-: Damlatmak.

köngüllerinte t.-1p 67

tapıg: Hizmet, hürmet, saygı.

t. udug [08]

tengri: Tanrı, yüce.

vişnu m(a)hakişvarı t.+de

t.+lerke 08

t. burhan [36], [40], 46, 50, [5]1

t. burhanka [35], 46

t. yèrinte 06

terkin: Derhal, hemen.

t. 31

tering: Derin.

t. yörügde 69

tez-: Kaçmak, uzaklaşmak.

t.- elim 31

t.-dim 58

t.-ip 38, 43, 49, 53

tè-: Demek, söylemek.

t.-di 55

t.-p 42, 52

t.p sözledi 59, 63

t.-p tèdi 56, 57, 58, 59, 60

t.-p tèdiler 21

t.-p tèrler 17, 23

t.-p tèştiler 12, 55, 70

t.-p y(a)rlıkadı [41], 47, 51

t.-p y(a)rlıkamış [37]

t.-p nomladi 61

t.-p nomlamış [36]

tèp t.-di 56, 57, 59, 60

tèp t.-diler 21

tèp t.-rler 17, 23

tèş-: Karşılıklı konuşmak, söyleşmek.

tèp t.-tiler 12, 55, 70

tèrkin: Cemaat (Rahipler cemaati),

topluluk.

t. 41,59

tınglama-: Dinlememek.

t.-tın 2[9]

tog-: Doğmak.

t.-galı 07

toyın: < Çin. tao jên Rahip.

gavdam t. 55

gavdam t.+ka 22

gavdam uguşlug t. 14

gavdam uguşlug t.+ka 18 törlüg: Türlü, çeşitli.

t. 01

öngi öngi t. 09

tört: Dört.

t. braman 05

t. padak [64], 67

törtegü: Dördü birlikte.

t. 29

törtünç: Dördüncü.

t. braman 49, [6]2

tözün: Asil.

t.+ler kèrtüsü [37], 4[1], 47, 5[2], 56, 59, 61, [63]

t. yavaş 13

turgurma-: Muhafaza etmemek, dâhil etmemek

t.-zun 26

tut-: Tutmak, taraftar olmak.

t.-daçı: 05

tu-: T1kamak, kapamak.

kulkakımın t.-yu 58

kulkakımıznı t.-yu 31

kulkakin t.-yu 38, 43, 48, 53

tükellig: Sahip.

çahşapatka t. 14

udug: Hizmet, hürmet.

tapig u. 09

ugur: Vakit, zaman. Firsat.

bir u.+da 11

uguşlug: Nesilden olan, soyundan gelen.

gavdam u. 14, 18

ulatı: Ve, başka, ayrıca, diğer.

u. 08

ur-: Koymak.

patırınta u.-alım [30]

patırınta ur.-dı 3[5], 40, 46, 50

utgurak: Kesin, açık.

u. 20

üçün: İçin.

èşidmişleri bar ü. 66

üçünç: Üçüncü.

ü. braman $44,48,60$

ün: Ses.

katıg ü.+in 3[6]

üze: İle; üzerinde.

ü. tutdaçı 05

vèt : Toh. ved < Skr. veda Hinduizm din 
bilgisi.

y. ök 21, 28, 46 .

v. 01

yèg: İyi, üstün.

vètyastan: < Toh. vidyāsthām < Skr.

y. adruk 24

vidyāsthāna Hinduizm din bilgisi konusu.

y. edgü 25

v. 0[1]

yèr: Yer, mekan.

vişnu: < Toh. Viṣnu < Skr. Viṣnu

brahmalok tengri y.+inte $0[6]$

Hinduizm'deki başlıca tanrılardan birinin yıgıl-: Toplanmak, yığılmak. adi.

v. 07

yakın: Yakın.

y.-1p sip 54

yme: Yine, de/da, dahi, bile

y. barip 45

y. $15,42,44,48,52,65,66$

yol: Yol, şeriat.

yarat-: Hazırlamak, meydana getirmek.

modak aş y.-1p 19

y. 51, 62 .

yörüg: Yorum, izah.

y(a)rlıka-: Buyurmak.

y.+inke 03

tering y.+de 69

yügür-: Yürümek.

y.-üp 30, 34

y.-üp bard1 38

tözün y. 13

yene: Yine.

y.-üp tezip bardı 53

y. 2[4] 


\section{Kaynaklar ve Kisaltmalar}

BHSD: Edgerton, Franklin (1977), Buddhist Hybrid Sanskrit Gramar and Dictionary, Volume II Dictionary, Delhi: Motilal Banarsidass Publication.

BT III Tezcan, Semih (1974), Das Uigurische Insadi-Sutra, Berlin: Akademie der Wissenschaften der DDR, Zetralinstitut für alte Geschichte und Archaologie. (Schriften zur Geschichte und Kultur des alten Orients 6. (Berliner Turfan Texte 3).

BT IX: Tekin, Şinasi (1980), Maitrisimit Nom Bitig, Die Uigurische Übersetzung eines Werkes der buddhistischen Vaibhāsika-Schule, Teil 1: Transliteration, Übersetzung, Anmerkungen, Berlin: Akademie Verlag. (Berliner Turfantexte IX).

BT XIII Zieme, Peter (1985), Buddhistische Stabreimdichtungen der Uiguren, Berlin: Akademie der Wissenschaften der DDR. (Zentralinstitut für Alte Geschichte und Archäologie. Schriften zur Geschichte und Kultur des Alten Orients. (Berliner Turfantexte 13).

BT XXV: Wilkens, Jens (2007), Das Buch von der Sündentilgung. Edition des alttürkisch-buddhistischen Kšanti Kılguluk Nom Bitig, I-II, Turnhout: Brepols. (Berliner Turfantexte XXV).

Çin: Çince

DLT: Dankoff, Robert - Kelly, James (1982, 1984, 1985), Mahmûd al-Kaşgarî: Compendium of the Turkic Dialects (Dîvân lugât at-Turk) I-III, Washington: Harvard Üniversitesi Basımevi.

EDPT: Clauson, Sir Gerard (1972), An Etymological Dictionary of Pre- Thirteenth-Century Turkish, Oxford: Clarendon Press.

Ehlers, Gerhard (1987), Alttürkische Handschriften. Teil 2:Das Goldglanzsutra und der buddhistische Legendenzyklus Dasakarmapathaavadanamala, Stuttgart: Steiner Verlag

Elmalı, Murat (2009), Dasakarmapathaavadānamālā Giriş-Metin-Çeviri-Notlar-Dizin-Tıpkıbasım, İstanbul: Marmara Üniversitesi Türkiyat Araştırmaları Enstitüsü: Basılmamış Doktora Tezi.

ETŞ: Arat, Reşid Rahmeti (1991), Eski Türk Şiiri, Ankara: TTK Yayınları.

KP Hamilton: Hamilton, James R. (1998), Budacı İyi ve Kötü Kalpli Prens Masalının Uygurcası, (çev. Ece Korkut-İsmet Birkan), Ankara: Simurg Yayınları.

Moerloose, Eddy (1980), "Sanskrit Loan Words In Uighur", Journal of Turkish Studies = Türklük Bilgisi Araştırmaları, 4 (1980), s. 61-78.

MW: Sir Monier, Williams (1964), Sanskrit-English Dictionary, Oxford: Clarendon Press.

OTWF: Erdal, Marcel (1991), Old Turkic Word Formation A Functional Approach to the Lexicon, Vol.I-II, Wiesbaden: Otto Harrassowitz.

Skr: Sanskritçe

Sogd: Soğdça

SuvKaya: Kaya, Ceval (1994), Uygurca Altun Yaruk. Giriş, Metin ve Dizin, Ankara: TDK Yayınları.

Şen, Serkan (2011), “Kutadgu Bilig'de Geçen Çomak 'Müslüman' Sözü Üzerine”, Doğumunun 990. Yılında Yusuf Has Hacib ve Eseri Kutadgu Bilig Bildirileri 26-27 Ekim 2009, Ankara: Türk Dil Kurumu Yayınları, s. 479- 483.

Şen, Serkan (2012), “'Sık' Sözcüğünün Kökeni Üzerine”, Turkish Studies 7/4, 513-517.

TD A: Poucha, Pavel (1955), Thesaurus Linguae Tocharicae Dialecti A, Praha: Státni Pedagogickè Nakladatelstvi.

TD B: Adams, Douglas Q (1999), A Dictionary of Tocharian B, Amsterdam-Atlanta: GA.

TekinKuan Tekin, Şinasi (1993), Uygurca Metinler I, Kuanşi İm Pusar (Ses İşiten İlâh). Vap hua ki atlı̆̆ nom çeçeki sudur (Saddharmapundarîka-sûtra), Ankara: TDK Yayınları.

Tiş: Yakup, Abdurishid (2005), Dišastvustik Eine altuigurische Bearbeitung einer Legende aus dem Catuṣparișat-sūtra, Wiesbaden: Veröffentlichungen der Societas Uralo-Altaica 71.

Toh: Toharca

TT VIII: Gabain, Annemaria von (1954), Türkische Turfan-Texte VIII, Texte in Brāhmischrift, Berlin: Akademie Verlag.

TT X: Gabain, Annemaria von (1959), Türkische Turfantexte X, Das Avadāna des Dämons Ātavaka, Bearbeitet von Tadeusz Kowalski + Aus dem Nachlass herausgegeben, Berlin: Akademie Verlag.

U II Müller, Friedrich Wilhelm Karl (1911), Uigurica II, Berlin: Verlag der Königl. Akademie der Wissenschaften.

Wilkens, Jens (2007), Das Buch von der Sündentilgung. Edition des alttürkisch-buddhistischen Kšanti Kılguluk Nom Bitig, I-II, Turnhout. (Berliner Turfantexte XXV). 
Wilkens, Jens (2010), Alttürkische Handschriften Teil 10: Buddhistische Erzähltexte Stuttgart: Franz Steiner Verlag.

Wilkens, Jens (2016), Buddhistische Erzählungen aus dem alten Zentralasien Edition der altuigurischen Daśakarmapathāvadānamālā (1-3), Turnhout (Berliner Turfantexte XXVII).

Zieme, Peter (1970). "Reviews: V. M. Nadelyaev [et alii] Drevnetjurkskij slovar", Central Asiatic Journal 14, 228-236. 
Ekler

Tipkıbasım

(Ön)

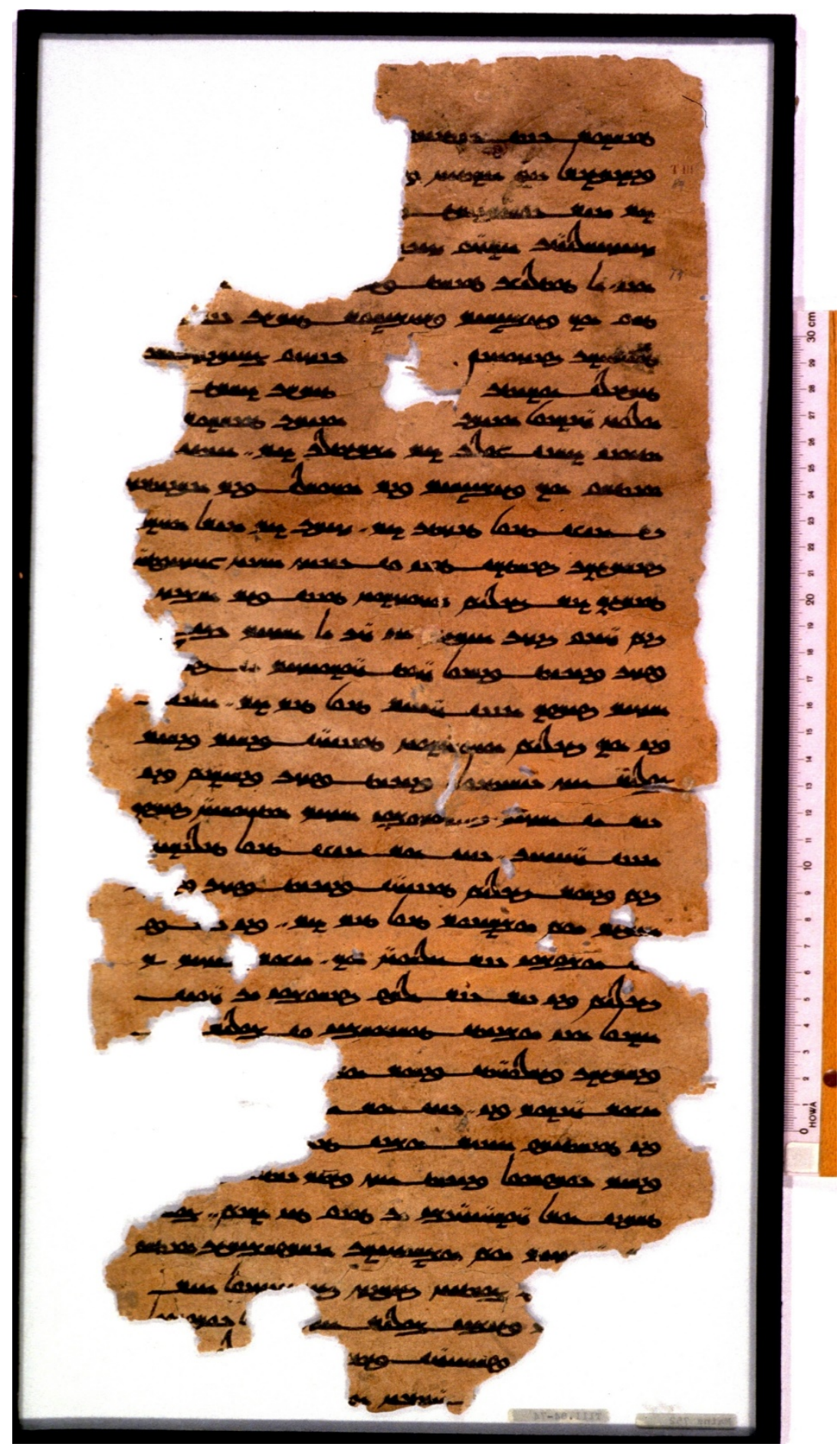

Depositum der BERLIN-BRANDENBURGISCHE AKADEMIE DER WISSENSCHAFTEN in der STAATSBIBLIOTHEK ZU BERLIN- Presußischer Kulturbesitz Orientabteilung 
(Arka)

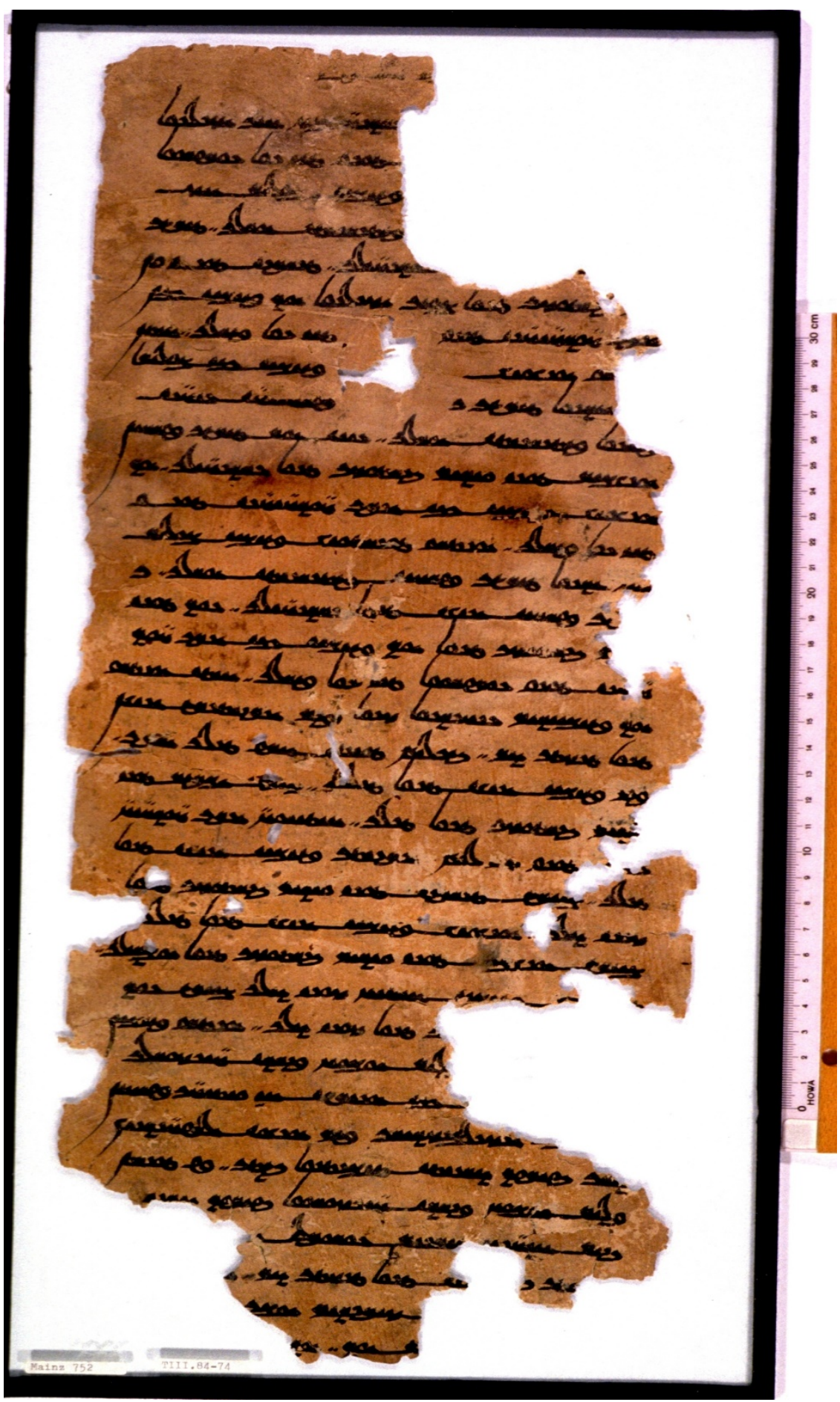

Depositum der BERLIN-BRANDENBURGISCHE AKADEMIE DER WISSENSCHAFTEN in der STAATSBIBLIOTHEK ZU BERLIN- Presußischer Kulturbesitz Orientabteilung 